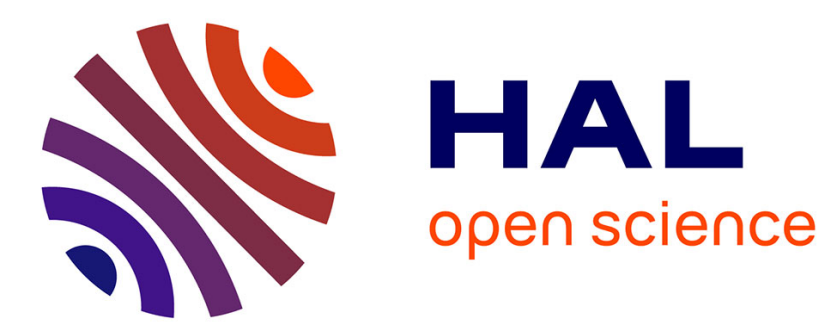

\title{
Dipolar Energy Anisotropy in Hexagonal Ferrites
}

\author{
G. Litsardakis
}

\section{To cite this version:}

G. Litsardakis. Dipolar Energy Anisotropy in Hexagonal Ferrites. Journal de Physique IV Proceedings, 1997, 07 (C1), pp.C1-341-C1-342. 10.1051/jp4:19971137 . jpa-00254780

\section{HAL Id: jpa-00254780 https://hal.science/jpa-00254780}

Submitted on 1 Jan 1997

HAL is a multi-disciplinary open access archive for the deposit and dissemination of scientific research documents, whether they are published or not. The documents may come from teaching and research institutions in France or abroad, or from public or private research centers.
L'archive ouverte pluridisciplinaire HAL, est destinée au dépôt et à la diffusion de documents scientifiques de niveau recherche, publiés ou non, émanant des établissements d'enseignement et de recherche français ou étrangers, des laboratoires publics ou privés. 


\title{
Dipolar Energy Anisotropy in Hexagonal Ferrites
}

\author{
G. Litsardakis
}

Department of Electrical \& Computer Engineering, Aristotelian University, 54006 Thessaloniki, Greece

\begin{abstract}
The dipolar energy contribution to the anisotropy of M- , W- and Y-type hexagonal ferrites is examined. The geometrical coefficients $k_{\mathrm{ij}}$ are given, so that a calculation for any hexaferrite with the same structure can be effected. Differences in the results of previous works are explained as due to a simplifying assumption, the validity of which is restricted. The ambiguity regarding dipolar energy anisotropy has been raised: dipolar energy anisotropy is dominant in BaZn$\mathrm{Y}$, while it is negligible in $\mathrm{M}$ - and W-type hexagonal ferrites. The results suggest that single ion anisotropy of the bipyramidal site is significant but the contribution of all the other sites is equally important.
\end{abstract}

\section{INTRODUCTION}

The origins of anisotropy in hexagonal ferrites were discussed for the first time by Smit and Duyvesteyn in Ref. [1]. They calculated the dipolar energy anisotropy and found that it is important only in $Y$ compounds, while in $M$ the calculated value was low and with opposite sign, compared to the experimental value. The anisotropy of $M$ (and $W$ compounds subsequently) was then attributed to single ion anisotropy of $\mathrm{Fe}^{3+}$ in the bipyramidal site of the structural block $\mathrm{R}$, which does not exist in the Y-type structure. The dipolar energy was calculated again by Lotgering et al [2] for some $\mathrm{M}, \mathrm{W}$ and $\mathrm{Y}$-type compounds. Comparing to the earlier results of [1], the values of $k_{\mathrm{ij}}$ (see eq. la) that they found were the same, except for those with $\mathrm{i}=\mathrm{j}$. In spite of this difference, the anisotropy constant $K_{1}$ resulted similar and their conclusions were the same: dipolar energy anisotropy is important only in the $\mathrm{Y}$ structure. However, calculations made by Isalgué et al [3] in $\mathrm{M}$ and $\mathrm{R}$ structures, and in W later [4], gave $K_{1}$ values very close to the experimental ones, with all but few $k_{\mathrm{ij}}$ equal to those of [2]. It was then proposed that anisotropy in both uniaxial and planar hexagonal ferrites is due to dipolar energy.

In this work a calculation of the dipolar energy anisotropy in $\mathrm{M}, \mathrm{W}$ and $\mathrm{Y}$ structures of hexagonal ferrites is performed, and previous calculations are discussed, showing that the importance of dipolar energy has to be reconcidered.

\section{CALCULATION OF DIPOLAR ENERGY ANISOTROPY}

In previous calculations dipolar anisotropy $K_{1}$ is analysed in coefficients $k_{\mathrm{ij}}$, which represent the geometric part of the interaction between two sublattices $i$ and $\mathrm{j}$ with magnetic moments $n_{\mathrm{i}}$ and $n_{\mathrm{j}}$ respectively (in Bohr magnetons):

$$
K_{1}=10^{3} \sum_{i \leq j} k_{i j} \cdot n_{i} n_{j}\left(\mathrm{erg} / \mathrm{cm}^{3}\right), \quad \text { where } k_{i j}=10^{-3} \mu_{B}^{2} \cdot N_{i} \sum_{n(j)}^{N} 3 \frac{\cos ^{2} \theta_{\ell n}(/ /)-\cos ^{2} \theta_{\ell n}(\perp)}{r_{\ell n}^{3}}
$$

The use of $N_{\mathrm{i}}$, the number of ions of sublattice $\mathrm{i}$ per volume unit, presumes that, for symmetry reasons, the dipolar energy is the same for each and every cation of a sublattice. So the interaction for only one ion of each sublattice was computed and then multiplied by the crystallographic multiplicity of the sublattice. This assumption is not generally true, and the correct way is to calculate the interaction for every ion in each sublattice separately:

$$
k_{i j}=10^{-3} \mu_{B}^{2} \cdot \frac{1}{2} \frac{1}{V_{c e l l}} \sum_{\ell(i)}^{L} \sum_{\substack{n(j) \\ n \neq \ell}}^{N} 3 \frac{\cos ^{2} \theta_{\ell n}(/ /)-\cos ^{2} \theta_{\ell n}(\perp)}{r_{\ell \mathrm{n}}^{3}}(\times 2)_{i \neq j}
$$

The results for $M, W$ and $Y$ type structures are given in tabl. 3-5.

Expression (1b) saves programming and computation time, but for certain sublattices, such as the $12 \mathrm{k}$ in $\mathrm{M}$, the $6 \mathrm{~g}$ and $12 \mathrm{k}$ in $\mathrm{W}$ and the $18 \mathrm{~h}$ in $\mathrm{Y}$, it yields $k_{\mathrm{ij}} \neq k_{\mathrm{ji}}$ (see tabl. 1-2). The values of kij in this case vary with the direction perpendicular to $\mathrm{c}$ axis, which is arbitrarily set in the calculations. Since only one half of the table of coefficients $k_{\mathrm{ij}}$ is required (because in eq. $1 \mathrm{a}$ it is $\mathrm{i} \leq \mathrm{j}$ ), and also it is not necessary to calculate for more than one direction in the basal plane 
$\{001\}$ (because the coefficients $k_{\mathrm{ij}}$ should be the same for any direction), the error resulting from (1b) has not been revealed up to now.

In Ref,[3] the projection direction [1,0] has been applied [5], while in Ref.[4] the use of [1,1] is reported, which explain the differences in the reported $k_{\mathrm{ij}}$ values of $12 \mathrm{k}$ and $6 \mathrm{~g}$. In Ref.[2] the results for $\mathrm{M}$ and $\mathrm{W}$ are practically the same with ours, although they were also obtained with the use of eq.(lb), while for $Y$ there are significant differences in the interactions with sublattice $\mathbf{1 8 h}$. The projection directions used in [2] are not reported, but we may comment that using eq. (lb), one can reproduce these $k_{\mathrm{ij}}$ values in two ways: Either calculating at certain projection directions, $45^{\circ}$ from the a axis in $M$ and $W, 15^{\circ}$ in $Y$, which however are not any particular directions in the hexagonal system, $[(1+\sqrt{3}) / 2,1]$ and $[(1 / 2)+$ $(\sqrt{3} / 2)(\sqrt{6}+\sqrt{2}) /(\sqrt{6}-\sqrt{2}), 1]$ respectively. Or taking the average of the extreme $k_{\mathrm{ij}}$ values that occur at different directions $([1,2,0]-[1,0,0]$ in $M$ and $W,[1,-1,0]-[1,1,0]$ in $X)$.

Table $1 . k \mathrm{ij}$ of $\mathrm{Y}$, using (lb)

\begin{tabular}{|c|c|c|c|c|c|c|}
\hline project. & $18 \mathrm{~h}-3 \mathrm{a}$ & $18 \mathrm{~h}-3 \mathrm{~b}$ & $18 \mathrm{~h}-6 \mathrm{c} 2$ & $18 \mathrm{~h}-6 \mathrm{c} 3$ & $18 \mathrm{~h}-6 \mathrm{c} 1$ & $18 \mathrm{~h}-18 \mathrm{~h}$ \\
\hline$[1,1]$ & 30.2 & 59.3 & -45.0 & -38.5 & 85.5 & -114.0 \\
{$[1,0]$} & 32.7 & 29.8 & 16.6 & 16.1 & 69.4 & -201.8 \\
{$[1,-1]$} & 33.5 & 20.0 & 37.1 & 34.3 & 64.0 & -231.1 \\
\hline
\end{tabular}

Table $2 . k \mathrm{jj}$ of $\mathrm{M}$, using ( $1 \mathrm{~b})$

\begin{tabular}{|c|c|c|c|c|c|}
\hline project & $12 \mathrm{k}-2 \mathrm{a}$ & $12 \mathrm{k}-4 \mathrm{e}$ & $12 \mathrm{k}-4 \mathrm{f} \mathrm{l}$ & $12 \mathrm{k}-4 \mathrm{f} 2$ & $12 \mathrm{k}-12 \mathrm{k}$ \\
\hline$[1,0]$ & 85.1 & 70.7 & -24.0 & -45.4 & -107.6 \\
{$[1,1]$} & 49.9 & 55.6 & 42.3 & 37.1 & -216.1 \\
{$[1,2]$} & 38.2 & 50.6 & 65.4 & 64.6 & -252.3 \\
\hline
\end{tabular}

Table 4. $k$ ij of $\mathrm{Y}$
\begin{tabular}{|l|c|c|c|c|c|c|}
\hline $\mathrm{Y}$ & $3 \mathrm{a}$ & $3 \mathrm{~b}$ & $6 \mathrm{c} 2$ & $6 \mathrm{c3}$ & $6 \mathrm{c1}$ & $18 \mathrm{~h}$ \\
\hline $3 \mathrm{a}$ & -5.2 & 5.7 & 45.1 & 11.7 & -16.9 & 22.7 \\
\hline $3 \mathrm{~b}$ & 5.7 & -5.2 & 9.6 & -49.6 & 12.7 & 38.9 \\
\hline $6 \mathrm{c} 2$ & 45.1 & 9.6 & -4.3 & 31.3 & -31.0 & -24.3 \\
\hline $6 \mathrm{c3}$ & 11.7 & -49.6 & 31.3 & -27.1 & 21.4 & 9.2 \\
\hline $6 \mathrm{c} 1$ & -16.9 & 12.7 & -31.0 & 21.4 & -6.8 & 6.1 \\
\hline $18 \mathrm{~h}$ & 22.7 & 38.9 & -24.3 & 9.2 & 6.1 & 172.3 \\
\hline
\end{tabular}

Table 3. kij of $\mathrm{M}$

\begin{tabular}{|l|c|c|c|c|c|}
\hline $\mathrm{M}$ & $2 \mathrm{a}$ & $4 \mathrm{e}(\mathrm{V})$ & $4 \mathrm{f}(\mathrm{IV})$ & $4 \mathrm{f}(\mathrm{VI})$ & $12 \mathrm{k}$ \\
\hline $2 \mathrm{a}$ & -5.5 & 9.8 & -57.3 & 15.4 & 61.7 \\
\hline $4 \mathrm{e}(\mathrm{V})$ & 9.8 & -5.5 & 16.6 & -33.2 & 59.8 \\
\hline $4 \mathrm{f}(\mathrm{IV})$ & -57.3 & 16.6 & -29.7 & 46.6 & 19.7 \\
\hline $4 \mathrm{f}(\mathrm{VI})$ & 15.4 & -33.2 & 46.6 & 19.7 & 9.6 \\
\hline $12 \mathrm{k}$ & 61.7 & 59.8 & 19.7 & 9.6 & -180.0 \\
\hline
\end{tabular}

Table $5 . k \mathrm{ij}$ of W

\begin{tabular}{|l|c|c|c|c|c|c|c|}
\hline $\mathrm{W}$ & $2 \mathrm{~d}$ & $4 \mathrm{f}(\mathrm{VI}) \mathrm{s}$ & $6 \mathrm{~g}$ & $4 \mathrm{e}$ & $4 \mathrm{f}(\mathrm{IV})$ & $4 \mathrm{f}(\mathrm{VI}) \mathrm{R}$ & $12 \mathrm{k}$ \\
\hline $\mathrm{2d}$ & -4.8 & 9.4 & 13.1 & 8.6 & 8.1 & -27.0 & 30.3 \\
\hline $4 \mathrm{f}(\mathrm{VI}) \mathrm{s}$ & 9.4 & -5.6 & 33.2 & -37.0 & -34.2 & 15.8 & 57.3 \\
\hline $6 \mathrm{~g}$ & 13.1 & 33.2 & -98.5 & -43.7 & 32.2 & 26.4 & 77.7 \\
\hline $4 \mathrm{e}$ & 8.6 & -37.0 & -43.7 & -0.4 & -22.6 & 16.7 & 59.6 \\
\hline $4 \mathrm{f}(\mathrm{IV})$ & 8.1 & -34.2 & 32.2 & -22.6 & -5.2 & 26.0 & -16.5 \\
\hline $4 \mathrm{f}(\mathrm{V}) \mathrm{R}$ & -27.0 & 15.8 & 26.4 & 16.7 & 26.0 & 11.6 & -13.7 \\
\hline $12 \mathrm{k}$ & 30.3 & 57.3 & 77.7 & 59.6 & -16.5 & -13.7 & -157.7 \\
\hline
\end{tabular}

\section{CONCLUSION}

As we can see in table 6 , in $M$ and $W$ the contribution of dipolar anisotropy is very small compared to the experimental value. In $\mathrm{BaZn}-\mathrm{Y}$ this kind of anisotropy is dominant, being about two times larger than the experimental value. In any case, besides dipolar anisotropy, a positive contribution of $1.6-4.6 \cdot 10^{6} \mathrm{erg} / \mathrm{cm}^{3}$ from other sources has to be taken into account in order to obtain the Table 6. Experimental and calculated $K_{1}$

\begin{tabular}{|c|c|c|c|c|c|c|}
\hline & \multirow[t]{2}{*}{$K 1 \exp$} & \multicolumn{4}{|c|}{$K_{1} \quad$ dipolar } & \multirow{2}{*}{$\begin{array}{l}\text { non-dipolar } \\
K 1(\text { exp-dip) }\end{array}$} \\
\hline & & [1] & [2] & {$[3,4]$} & this work & \\
\hline$\overline{\mathrm{M}}$ & 4.4 & -1.5 & 0.2 & 4.2 & -0.2 & 4.6 \\
\hline W & $2.8-3.8$ & - & 0.3 & $1.9-2.1$ & 0.06 & $2.8-3.8$ \\
\hline $\mathrm{Y}$ & -1.6 & -4 & -4 & - & -3.2 & 1.6 \\
\hline
\end{tabular}
experimental values. The planar anisotropy of $Y$ compounds is determined both by the large negative dipolar anisotropy and by the lack of the bipyramidal site. A comparison of $K_{\mathrm{I}} \exp -K_{\mathrm{I}}$ dip in all three structure types indicates that the role of the bipyramidal site may be significant but the total contribution of the other sites is also important.

A reliable calculation of dipolar energy contribution to the anisotropy of $\mathrm{M}$ - and $\mathrm{Y}$-type hexagonal ferrites has been effected. The results reverse the conclusions of the more recent calculations and confirm the earlier ones, although in all previous cases $k_{\mathrm{ij}}$ were not calculated correctly.

\section{Acknowledgments}

The author wishes to thank A.Collomb for suggesting the subject, A.Isalgue and J.P.Mignot for providing their calculation programs, D.Samaras and G.Kanellis for helpful discussions.

\section{References}

[1] Casimir H.B.G., Smit J., Enz U., Fast J.F., Wijn H.P.J., Gorter E.W., Duyvestein A.J.W., J.D.Fast J.D. and J.J.Jong J.J. Le Journal de Physique et le Radium, $\mathbf{t} 20$ (1959) 360-373

[2] Lotgering F.K., Locher P.R. and vanStapele R.P., J.Phys.Chem.Solids, 41 (1980) $481-487$

[3] Isalgue A., Obradors X. and Tejada J., J.de Physique, C6, 146 (1985) 345-348

[4] Collomb A., Abdelkader O., Isalgué A. and Mignot J.P, phys.stat. sol. (a), 97 (1986) 896-904

[5] Isalgué A., private communication 